\title{
Therapeutic use of human growth hormone
}

\author{
A. S. MASON
}

From the London Hospital, Whitechapel, London E1
A great deal is known about the therapeutic effect of human growth hormone (HGH) on short stature. Raben (1958) reported the acceleration of growth in hypopituitary subjects given $\mathrm{HGH} 18$ years ago. The species specificity of growth hormone means that we must rely on hormone extracted from human pituitaries. It is likely to be a long time before HGH is synthesised and various 'soups' of digested ox pituitary have been of no avail. The only immediate hope for an alternative to $\mathrm{HGH}$ is the isolation and synthesis of the growth hormone releasing hormone. If the syndrome of isolated growth hormone deficiency is due to a lack of this hypothalamic hormone rather than an inability of the pituitary itself to secrete growth hormone the logical therapy is obvious.

The amount of 'clinical grade' HGH available from human pituitaries obtained at necropsy will depend largely on the efficiency of the extraction procedures. Raben's (1959) method using acetonedried pituitaries yielded 4.4 IU per gland. The modification of Wilhelmi's method by Mills et al. (1969) obtained about 7.2 IU per gland. Methods using fresh frozen pituitaries vary from that of Roos et al. (1963) to the modern development by Lowry (1977) that produced monomer growth hormone at a yield of $16.0 \mathrm{IU}$ per gland. The antigenicity of these products is of importance. The Raben preparation, widely used, promoted antibody formation in a number of patients. The preparations from frozen pituitaries seem less antigenic. The biological potency of each batch of HGH has to be assayed, because it varies considerably, and the potency of the finally ampouled material has to be checked.

\section{Indications for HGH treatment}

The indications for using $\mathrm{HGH}$ to treat short stature are clear from many well-conducted clinical trials in several countries. The HGH will accelerate growth only in those whose short stature is due to deficient growth hormone secretion. The trouble lies in finding a valid measure of this deficit. The absence of immunoassayable HGH in a patient's serum is a $\vec{\circ}$ good indicator of an absence of biologically active $\overrightarrow{\vec{\omega}}$ HGH. Nevertheless, since normal growth hormone $\stackrel{5}{\circ}$ secretion is intermittent it has to be shown that HGH is absent after the pituitary has been stimula- is ted. A serum level of $\mathrm{HGH}<7 \cdot 0$ IU/l after appropri- $\overrightarrow{\dot{v}}$ ate pituitary stimulation indicates definite deficiency, $\overrightarrow{-}$ and levels of 7.0 to $14.0 \mathrm{IU} / \mathrm{l}$ strongly suggest partial in deficiency.

There is still the question of what constitutes an appropriate stimulus to pituitary secretion of $c$ growth hormone. As a method of quickly excluding growth hormone deficiency there is nothing better than finding a serum concentration of over $14.0 \mathrm{IU} / \mathrm{l}$, the blood sample being taken from a fasting, fright- $\vec{\varphi}$ ened child by a clumsy phlebotomist. The whof o range of formal testing procedures was reviewed by Frasier (1974). Despite the potential hazards insulin-induced hypoglycaemia seems to be the most reliable method. Arginine infusion is as cumbersome but less reliable. Penny et al. (1969), $\mathbb{D}$ however, showed that response to different stimuli $\stackrel{2}{\Rightarrow}$ could vary. Comparing insulin and arginine stimulation in 52 normals, 32 responded to both stimuli but 10 responded only to insulin and 10 only to arginine.

Both these tests are very unphysiological. A more natural approach is to measure $\mathbf{H G H}$ levels during 'slow wave' sleep, when $90 \%$ of the 24-hour secretion of HGH occurs. Wise et al. (1975) reported a case of good response to insulin and arginine but no HGH detectable during sleep. The patient was of short stature and showed a good growth response to 5 injected HGH. Thus the child with clinical evidence $\rightarrow$ of growth hormone deficiency may lack adequate growth hormone secretion despite the fact that $N$ abnormal stimuli can elicit HGH secretion. On the other hand, thyroxine deficiency so blunts the 0 capacity of a normal pituitary to secrete growth $\omega$ hormone when stimulated that such tests cannot be interpreted correctly until thyroxine deficiency has $\stackrel{0}{C}$ been corrected. The curious entity of psychological $\mathbb{D}$ deprivation has the same effect. Straightforward? obesity also diminishes pituitary responsiveness so that a false impression of partial growth hormone deficiency may be given. 
Types of growth hormone deficiency

The types of growth hormone deficiency can be classified physiologically. Absence of the hypothalamic growth hormone releasing hormone is presumed in psychological deprivation and is probably the prime cause in many instances of isolated growth hormone deficiency. Direct damage to the anterior pituitary, particularly in children with craniopharyngioma, is an obvious cause of growth hormone deficiency-often, but not always, associated with deficiencies in other anterior pituitary hormones. Finally, the action of growth hormone on target cells may be inhibited by excess cortisol or its synthetic analogues or, since growth is dependent on the release of somatomedin (or, more correctly, somatomedins) by growth hormone, a failure of growth hormone may be due to a deficiency of somatomedins. Thus the Laron dwarf (Laron et al., 1966; Daughaday et al., 1969) has all the clinical characteristics of isolated growth hormone deficiency but has normal serum levels of $\mathrm{HGH}$ and does not grow in response to injected $\mathrm{HGH}$. The serum level of somatomedin is very low and does not increase after injections of $\mathbf{H G H}$.

Hall (1971) showed that a single intravenous injection of $\mathrm{HGH}$ in a normal subject produced a short-lived rise in serum concentration of $\mathrm{HGH}$ but a slow sustained rise in somatomedin concentration, falling gradually over many hours. The direct relation of somatomedin to growth indicates that the frequency of injections of $\mathrm{HGH}$ in treatment should be related to the levels of circulating somatomedin rather than to the serum levels of $\mathrm{HGH}$. The recent development of receptor assays, particularly for somatomedin $\mathrm{C}$, is likely to be of practical importance in the future monitoring of therapy.

The clinical picture of growth hormone deficiency is seen most clearly in cases of isolated growth hormone deficiency. Admittedly this monotrophic deficit may later show evidence of gonadotrophin or TSH deficiency. The child deprived of growth hormone will have had a normal birth weight but will be far shorter than expected from parental height. The bone age will be much delayed but the height will be short even for the bone age. There will be relative plumpness, the subcutaneous fat being increased in relation to the thin bones and muscles.

\section{Response to treatment}

Such children respond very well to $\mathrm{HGH}$-better than those with such lesions as craniopharyngioma. Subcutaneous fat diminishes immediately and height-gain velocity greatly accelerates to outstrip by far the rise in bone maturation velocity. This is the opposite of the effects of sex steroids, which increase bone maturation far faster than they increase height. Therapy in cases of growth hormone deficiency is a true replacement treatment and therefore has to be continued over many years until an acceptable adult height is reached. Ideally the diagnosis should be made in infancy, when the slow rate of growth should alert the doctor to the possibility of growth hormone deficiency. Early and continued treatment will prevent dwarfism. The results are much better than those after treatment of established dwarfism. Disappointingly, even now the diagnosis of growth hormone deficiency is often delayed until the child is about 12 years old.

Using quarterly measurements of height, the height-gain velocity induced by HGH in a growth hormone deficient child is maximal in the first three months of therapy and very gradually falls after that. The first year of treatment adds more inches than any subsequent year although the height-gain velocity remains high enough to contribute significantly to statural growth. This fall off in response is in the nature of a catch-up growth curve, as seen, for example, in the treatment of primary hypothyroidism. It has to be distinguished from diminution of response due to some adverse agent.

Failure of the growth hormone deficient child to respond adequately to HGH may rarely be due to antibody formation. The antigenicity of preparations of HGH varies. The Raben preparation has the worst reputation, but the greater use of modified Wilhelmi preparations has shown that they also provoke antibody formation. The Roos preparation from fresh frozen glands seems to be a far less potent antigen. The modern preparations have not been used enough for any conclusion to be drawn. Frasier et al. (1974) found antibodies to HGH in $60 \%$ of his patients but the mean growth rate was the same for the group with antibodies as for that without them. Illig (1972) considered that antibody formation was more likely to occur in patients who had never had any endogenous growth hormone secretion. However, in terms of the biological response to $\mathrm{HGH}$ it is not the presence of antibodies that matters but their capacity to bind HGH that determines interference with growth.

Of the more common factors that diminish the effect of HGH lack of thyroxine and excess of cortisol are very important. Minor excesses of cortisol or its synthetic analogues have a considerable inhibitory effect on HGH. This may explain why a hypopituitary child on replacement therapy usually responds to $\mathrm{HGH}$ with only about $65 \%$ of the growth seen in treated cases of isolated growth hormone deficiency. It is a real clinical problem to 
find a dose of glucocorticoid that keeps the patient safe from the disasters of adrenal failure without severely limiting the growth response to HGH. Any intercurrent illness will diminish growth response. In those with craniopharyngiomas an otherwise inexplicable slowing in induced growth is an alarm that something has gone amiss with the tumour situation. It is an odd fact that in the MRC trial of HGH all 20 males with craniopharyngioma have responded adequately to treatment but 10 of the 30 females have responded inadequately.

\section{Dosage}

Clinical hints that a growth hormone deficient child will respond well to $\mathrm{HGH}$ are the absence of any other hormonal disturbance, good general health, extreme shortness, and a low bone age. The actual age matters little, but there is a correlation between induced height-gain velocity and low bone age (Preece and Tanner, 1976). The pretreatment heightgain velocity is a poor guide to therapeutic response but there is little to choose between slow and very slow.

Under the best conditions $\mathrm{HGH}$ should give a height gain of about $10 \mathrm{~cm}$ in the first year. It is difficult to be sure of the right dose because reported regimens of treatment are so different and the comparable potency of the HGH used uncertain. In most countries around 10 IU weekly is given in two or three injections. In the MRC trial 10 or 20 IU has been given weekly in twice-weekly injections. Over 10 years the height gain with the higher dose may be $10 \mathrm{~cm}$ more than with the lower dose (Preece et al., 1976). However, it looks as if thrice-weekly injections are somewhat more effective than the twiceweekly regimen and that the most appropriate dose, having regard to the shortage of $\mathrm{HGH}$, is about 10 IU per week. Several authors have reported various regimens of intermittent treatment (Pertzelan et al., 1976), but the height gain seems to be related to the number of months of treatment, as it is with continuous therapy. Claims that intermittent therapy does not have the disadvantage of a fall-off in heightgain velocity as treatment proceeds are not clear from the data presented. It is, of course, an economical way of using $\mathrm{HGH}$.

Finally, there is the problem of sexual maturation. Sex steroids, produced in normal puberty or administered as therapy, always induce a height growth accompanied by a disproportionately rapid advance in bone age, thus cutting down the time left for statural growth. Therefore in patients who do not go into spontaneous puberty there is the choice of more height gain with prolonged HGH therapy or less eventual height but adequate sexual development caused by sex steroid administration. The normal interaction between growth hormone and sex steroids has been the subject of much debate. 으 Prader and his colleagues (see Zachmann et al., 1976) have shown that HGH is necessary as as permissive factor to allow testosterone to be fullyo effective as an androgen and as a somatic growth $\underline{\overline{\bar{D}}}$ promoter.

Because HGH has been in very short supply (and ${ }_{\Omega}^{\Phi}$ will probably continue to be) its use in the treatment of short stature has been most fully documented. The $\overrightarrow{ }$ indications for its proper use and its effects are now: known well enough to provide excellent guidelines $\vec{\omega}$ for the future.

I thank Dr M. A. Preece for his help in the prepara-is tion of this paper.

\section{References}

Daughaday, W. H., Laron, Z., Pertzelan, A., and Heins,, J. N. (1969). Definitive sulfation factor generation: apossible etiological link in dwarfism. Transactions of the Association of Americ an Physicians, 82, 129.

Frasier, S. D. (1974). A review of growth hormone stimulations tests in children. Pediatrics, 53, 929.

Frasier, S. D., Aceto, T. Jr, Hayles, A. B., Parker, M. L., andMeyer-Bahlburg, H. F. L. (1974). Collaborative study of the effects of human growth hormone in growth hormones deficiency. II. Development and significance of antibodies to human growth hormone during the first year of theray Journal of Clinical Endocrinology and Metabolism, 38,

Hall, K. (1971). Effect of intravenous administration of $\mathrm{HGH}$ on sulphation factor activity in serum of hypopituitary patients. Acta Endocrinologica, 66, 491.

Illig, R. (1972). In Human Growth Hormone, edited by A. Stuart Mason. Heinemann, London.

Laron, Z., Pertzelan, A., and Mannheimer, S. (1966) $\frac{O}{3}$ Genetic pituitary dwarfism with high serum concentrationof growth hormone. Israel Journal of Medical Science, 2 ह 152.

Lowry, P. J., Mclean, C., Lumley Jones, R., and Satgunas ingam, N. (1977). Purification of anterior pituitary and $\bar{P}$ hypothalamic hormones. Journal of Clinical Pathology 30? Supplement (Association of Clinical Pathologists), 7, 16

Mills, J. B., Ashworth, R. B., Wilhelmi, A. E., and Stockel' Hartree, A. S. (1969). Improved method for the extraction and purification of human growth hormone. Journal of Clinical Endocrinology and Metabolism, 29, 1456.

Penny, R., Blizzard, R. M., and Davis, W. T. (1969). Sequen tial arginine and insulin tolerance tests on the same dayo Journal of Clinical Endocrinology, 29, 1499.

Pertzelan, A., Kauli, R., Assa, S., Greenberg, D., and Laron Z. (1976). Intermittent treatment with human growth hormone (GH) in isolated GH deficiency and in multiple pituitary hormone deficiencies. Clinical Endocrinology, 5 W 15.

Preece, M. A., and Tanner, J. M. (1976). The diagnosis an management of growth hormone deficiency. Minervo Endocrinologica, 1, 42,

Preece, M. A., Tanner, J. M., Whitehouse, R. H., and Cameron, N. (1976). Dose dependence of growth response to human growth hormone in growth hormone deficiency Journal of Clinical Endocrinology and Metabolism, 42유 477.

Raben, M. S. (1958). Treatment of a pituitary dwarf witt 
human growth hormone. Journal of Clinical Endocrinology, 18,901 .

Raben, M. S. (1959). Human growth hormone. Recent Progress in Hormone Research, 15, 71.

Roos, P., Fevold, H. R., and Gemzell, C. A. (1963). Preparation of human growth hormone by gel filtration. Biochemica et Biophysica Acta, 74, 525.

Wise, P. H., Burnet, R. B., Geary, T. D., and Berriman, H. (1975). Selective impairment of growth hormone response to physiological stimuli. Archives of Disease of Childhood, 50, 210.

Zachmann, M., Aynsley-Green, A., and Prader, A. (1976). Interrelations of the effects of growth hormone and testosterone in hypopituitarism. In Growth Hormone and $\mathrm{Re}$ lated Peptides (International Congress Series, 381), edited by A. Pecile and E. E. Müller, p. 286. Excerpta Medica, Amsterdam. 